\title{
SUSTAINABILITY THROUGH DIRECTED CHANGE IN THE VISIONARY UNIVERSITY: FROM PREDICTING TO PRODUGING THE FUTURE
}

\author{
Adrian Curaj', Mihai Păunică르, Andreea Popa ${ }^{3}$, Cosmin Holeab ${ }^{4 *}$ \\ and Octavian-Dragomir Jora ${ }^{5 *}$ \\ ${ }^{1) 4)}$ The UNESCO Chair on Science and Innovation Policies, National School \\ of Political Studies and Public Administration, Bucharest, Romania. \\ ${ }^{2) 5}$ The Bucharest University of Economic Studies, Romania. \\ 3) The Executive Agency for Higher Education, Research, Development \\ and Innovation Funding (UEFISCDI), Bucharest, Romania.
}

Please cite this article as:

Curaj, A., Păunică, M., Popa A., Holeab, C. and Jora, O.D., 2020. Sustainability Through Directed Change in the Visionary University: From Predicting to Producing the Future. Amfiteatru Economic, 22(55), pp. 905-919.

\section{Article History:}

Received: 27 March 2020

Revised: 12 May 2020

Accepted: 26 June 2020

DOI: $10.24818 / \mathrm{EA} / 2020 / 55 / 905$

\begin{abstract}
The sustainability of a university can be questioned from the perspective of three functional goals, henceforth setting the analytical framework: (i) the development of suited knowledge (dynamic and evolving, mirroring the complexity of the socioeconomic environment, definitely internationalised and future-oriented), (ii) the development of students' skills, as future workforce (valuing the knowledge) and (iii) the development of institutional capacities, in agile constructions (adequate to face the first two challenges). Such a vision of sustainability in higher education treats change as the very "fuel" of sustainability, not as a threat, an ordeal, or a risk factor; it also transfers the notion of "being sustainable" from an attribute of a state to that of a process; and at the same time, it is precisely a process that does not simply "happen", but is purposefully driven by action, and it comprises a multilevel and polyvalent reality, where prognosis is to be accompanied by proactivity, forecast by foresight, and piecemeal approaches by systemic ones. This essay thoroughly contextualizes such a conceptualization of the sustainable university. It aims to identify some problems that higher education encounters in the managerial, teaching and research processes, that is in the creation and transfer of knowledge, within the current international institutional setup. It also seeks to explain how a culture of collaboration can be developed in such a way that good practices and knowledge are to be shared, obstacles are to be overcome, and efforts are to be capitalized upon in this context. It is essential to understand how teachers, students and graduates can all become prepared to muster and master such change, instead of being led by it or becoming its victims, governing both normalcy and disruptions. It also outlines a strategic understanding and a performance "kit" with innovative approaches, tools and other resources for universities aspiring to carry out plenary sustainability; thence, even if this logic might (not) have been tried out within present-day Romanian higher education, it should be part of its future tense.
\end{abstract}

Keywords: higher education, sustainable development, globalization, change, technology, management, leadership.

JEL Classification: I23, I25, O33, O34, O36, F53, F55.

* Corresponding authors (equal contributions), Cosmin Holeab - cosmin.holeab@gmail.com and Octavian-Dragomir Jora - octavian.jora@ rei.ase.ro. 


\section{Introduction}

A commonsense and commonplace dictum holds that better questions prepare better answers. This holds all-the-more true when those asking the questions are, at the same time, the ones most able to find the proper answers, too. When speaking about the university, the identity between the "inquirers" and the "respondents" is a critical asset in delivering the implicit aim of each and every higher education institution (before being abundantly explicit in academic literature - viz., the collection of topics from Amfiteatru Economic, Vol. 21, No. 54, March 2020): that is its sustainability. We speak of a multilevel and multifaceted kind of sustainability, in which the commandments of preserving a specific tradition behind it cohabit with those of facing the challenges ahead.

If we can build up on this logic of fine-tuning questions prior to refining answers, some concerns qualify for the intellectual cannonade:

- What are the obstacles that higher education institutions worldwide have found or will encounter in their quest for sustainability and what is to be done in this regard? [For instance: which are the possible hurdles while pursuing the aim of implementing in universities the mindset of the 2030 Agenda for Sustainable Development, reflected in and resonating with all their functions and missions (e.g., institutional processes, teaching, research, knowledge creation and transfer, and community engagement)? Obviously, there is a great need to discover and develop an effective way to nurture a rich culture of institutional collaboration, able to assist the process of sharing the best practices and relevant knowledge internationally, and to overcome barriers and to capitalise on efforts.]

- What are the uncertainties, the technology trends, the weak signals of the plausible near "futures" and how are we prepared for these? [For instance: how can universities contribute to the creation of the knowledge underlying the ethics standards, the norms, the contingency plans? The question is relevant since, soon, we will be witnessing the first commercial spacecraft that will take people into space for fun instead of research and the first galactic ride sharing company that will transport cargo into orbit; and we will see the birth of the first genetically-edited humans. Or, putting it more specifically: what lies beyond the digital frontier? This is one pertinent concern, for in mapping the future, the digital transformation promises responses to various pressures and to disruptive change.]

With relevancy for Romania, universities are expected to become networked and open institutions by 2030; the networks of universities will be territorially distributed, will adopt challenge-based approaches and will function by co-envisioned long-term strategies focused on sustainability, excellence and European values. For Romania, as a member of the European Union in parallel with its global exposure, it becomes important to see: How can universities and the European networks of universities be ready for this digital transformation? How can they collect and make sense of the huge bundles of data? How will they fuel impactful digital transformation by combining technology with the crosspollinating knowledge coming from science and business for new opportunities? How will they move beyond the frontier of (seemingly) random acts of digitalized life?

Concerning the sustainability of a university, we consider it as being defined by three framing endeavours: (a) the development of the relevant knowledge (which can be defined as dynamic, attending to the complexity of the socio-economic environment, international, as well as future-oriented), (b) the development of the students' skills in preparing the future workforce (this being done precisely through the very processing of the indicated 
kind of knowledge), (c) the expansion of institutional capacities onto the edification of an agile construction (fitted to meet both aforementioned challenges). It is worth reinforcing the fact that our view, as reflected in this paper, does not single out a particular sustainable development issue, but builds upon multiple, yet correlated, inquiries into the functional premises of tackling "university sustainability" concerns.

The institutionalised benchmarks to which we will refer in this paper were chosen based on their ability to locate the intricate landscape in which the universities activate: (1) the Sustainable Development Goals, (2) the emerging global technology trends, (3) the Bologna Digital process, as well as (4) the European Universities Initiative. After surveying them, we indicate a full-fledged (conceptual and methodological) framework - a strategic understanding and performance "toolbox" -, consisting of innovative approaches, tools and other resources for universities: (1) a conceptual framework devoted to foresight activities in universities with a dedicated focus on the issue of (2) weak signals in strong connection with technological change, and (3) a complex framework of blended semantic and network analysis that is linked to Big Data challenges.

The next section briefly refers to the developments related to the four major "benchmarks" with which our own analysis communicates.

\section{From assessing to addressing the challenges}

\section{Sustainable Development Goals}

Following the adoption of the 2030 Agenda for Sustainable Development, in 2015, by the United Nations member states, the academic world is buzzing with various initiatives of higher education institutions worldwide that have been addressing, collectively and individually, the major challenges the document had revealed. Scientific and position papers on the role of higher education in addressing the Sustainable Development Goals (SDG) are available, higher education sustainability initiatives (with very broad participation) have been launched, platforms for sharing best practices are running, while the Times Higher Education international ranking has launched University Impact Rankings by SDG (looking at how universities support the SDGs through collaboration at international level, promotion of best practices and publication of new data).

With commitments from over 300 universities from around the world, the Higher Education Sustainability Initiative (from the 16 major ongoing action networks for the SDGs) was launched in 2012 by the United Nations, providing these institutions with an interface between higher education, science, and policy making. An open space of institutional collaboration and knowledge sharing, attempting to maximise the impact of 365 strategic partnerships that are addressing all the 17 SDGs (see https://sustainabledevelopment.un.org/partnerships/hesi).

The SDG Accord, launched in 2017 by the Environmental Association for Universities and Colleges (EAUC), with the support of over 60 sustainability networks and institutional partners, is currently endorsed by 262 universities, 27 student unions and 141 supporting organisations (and 1055 individuals from higher education systems) from around the world (see https://www.sdgaccord.org/). The network is providing all sorts of resources for higher education institutions in their endeavours to address the SDGs (e.g., webinars and case studies) and progress reports from universities or colleges.

Vol. $22 \cdot$ No. $55 \cdot$ June 2020 
In September 2019, the Global University Network for Innovation (GUNi) published a report on the challenges of implementing the 2030 Agenda at higher education institutions, offering a series of recommendations for the university communities (GUNi, 2019).

\section{Emerging global and technology trends}

Looking back ten-to-five years ago at the news headlines, the fervent public welcoming of the now-distant cutting-edge technologies and challenges of the day seems far-fetched. The rate at which technology is evolving reveals the inherent challenges in (keeping the pace in) advancing, validating and accommodating the sectoral knowledge concerning technological breakthroughs. The capacity of universities to grasp and instrument the technological changes in their teaching, research and institutional activities, the way they link with and, moreover, partake in the subsequent promotion and diffusion of technology are of unquestionable importance for the society.

There are numerous knowledge resources available that capture the generation of technology and look into plausible uncertain "futures" (scenarios). They offer valuable insights by spotting emerging technology trends that are likely to open new "avenues" for pursuing new strategic goals, usually addressing a timespan of one-to-two years. Such examples of structured knowledge are the annual tech trends reports published by Deloitte and the Future Today Institute (Deloitte Insights, 2019; Future Today Institute, 2019). For instance, the Deloitte report of 2019 is providing an overview of the trends of technological change over the last decade (Figure no. 1).

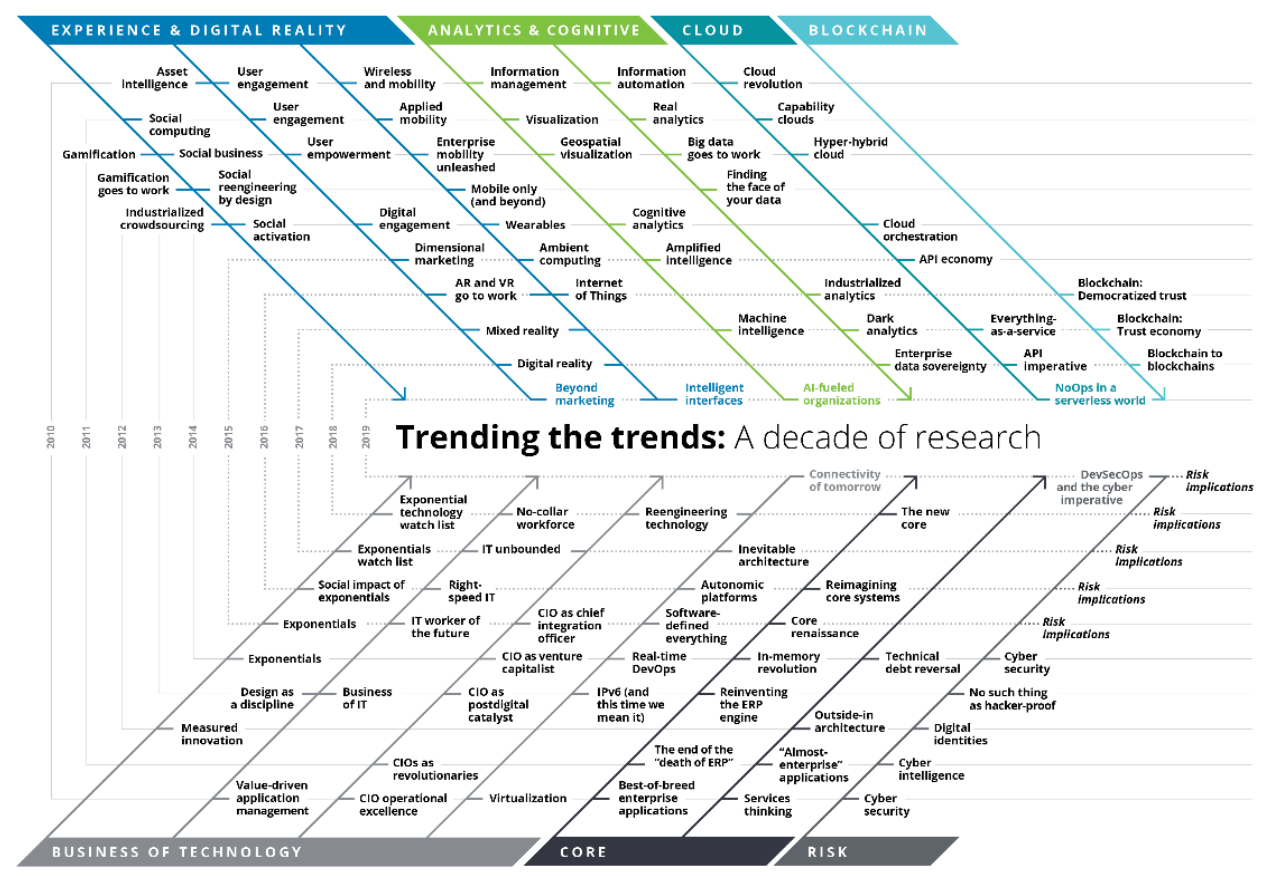

Figure no. 1. Trending the trends (A decade of research) Source: Deloitte Insights, 2019, p. 2. 
Apart from inspiring a professional practice, the essential rationale of these resources is that while one cannot settle the future uncertainties, organisations can prepare to think strategically using data-driven signals and trends, based on connecting the knowledge instead of mere predictions. The advisable approach in "consuming" this kind of knowledge is to make the connections between the trends, the organisation and the sector, to think exponentially and act incrementally.

\section{Bologna Digital}

As the Bologna Process advances, the key challenges of opening up higher education, improving the quality of teaching and learning, reforming assessment and recognition, and promoting internationalisation and mobility remain the same for all countries in the European Higher Education Area. A recent white paper (Rampelt et al., 2019) is arguing that digitalisation can significantly inspire a new paradigm in managing higher education.

The abovementioned paper scrutinizes the current developments, but also looks at the future of higher education, offering " $a$ pathway between the current situation in higher educations and future developments, when digitalisation is viewed more holistically" (Rampelt et al., 2019, p. 7). The purpose of the report is to open the public debate on how to harness the higher education digitalisation across the European Higher Education Areaalso a concern of the Bologna Process Researchers' Conference series (http://fohebprc.forhe.ro/).

\section{European University Initiative}

Reacting to the social-economic challenges and changing nature of the educational landscape across the European Union and responding to the call from the European Council, in 2017, the European Commission launched the European University Initiative co-developed by higher education institutions, student organisations, member states and the Commission. European universities are meant to be(come) "transnational alliances that will become the universities of the future, promoting European values and identity, and revolutionising the quality and competitiveness of European higher education" (EC website, Education and Training).

They will include partners from all regions and types of higher education institutions, will function based on long-term strategy focused on sustainability, excellence and European values, will jointly offer student-centred curricula and will tackle the biggest issues facing Europe in an inter-disciplinary, challenge-based approach. To this call, three Romanian universities have already joined the three consortia devoted to assisting the process: CIVICA - The European University of Social Sciences, CIVIS - a European civic university alliance) and CONEXUS - European University for Smart Urban Coastal Sustainability, in the first wave, from June 2019.

\section{Looking ahead. Foresight in universities}

In order to adequately address the complex issues of sustainability, universities need to widen their view beyond the short-term actions and targets, beyond the known environment, and explore new challenges and future opportunities. Therefore, foresight is a key approach in exploring the future and articulate future-oriented strategies and policies.

Vol. $22 \cdot$ No. $55 \cdot$ June 2020 
Over the last 30 years, as a specific area of forward-looking activities, futures studies methodologies supporting decision-making (particularly across Europe) have been defined under the "foresight" heading, introduced by H.G. Wells in 1932 (Wells, [1932] 1987). The focus and aims of such activities are mainly related to public policy formulation, "not displacing existing decision-making and planning processes - rather, complementing and informing them so as to increase their effectiveness" (Miles et al., 2002, p. 35). Emerging from technology studies in the '70s (in Japan and the USA), the foresight methodology has gradually developed into a systematic, participatory, future-intelligence-gathering and medium-to-long-term vision-building process (European Commission, 2010). D. Loveridge, a referential scholar of the field (focusing on the relation between futures and systems thinking), defined foresight as being the art and science of anticipating future (Loveridge, 2009). In order to better understand the term or to envelop the phenomenon in a nutshell, a commonly referred to definition of foresight is provided by the foresight guide developed at the University of Manchester in 2002: "the application of systematic, participatory, futureintelligence gathering and medium-to-long-term vision-building processes to informing present-day decisions and mobilising joint actions" (Gavigan et al., 2003, p. XI).

The international practices of foresight for science, education, technology and/or innovation policies have been grouped into five generations of foresight - as "ideal types" of foresight exercises which have arrived rather progressively, but are still employed with specific variations from one case to another, and which take up different types of policy-related knowledge and challenges and also involve different combinations of experts and stakeholders participation approaches. They range from (1) technology forecasts, (2) technology and markets, (3) technology, markets and the social domain, to (4) distributed actors in an innovation ecosystem, (5) tailored approaches in a Science \& Innovation ecosystem (Păunică, 2009; Cassingena-Harper, 2013). Further describing the connection between foresight and Science \& Technology (systems), Cassingena-Harper indicates that "it involves intense iterative phases of open reflection, networking, consultation, and discussion leading to the joint refining of future visions and the common ownership of strategies, with the aim of exploiting long-term opportunities opened up through the impact of science, technology and innovation on society. It is the discovery of a common space for open thinking on the future and the incubation of strategic approaches. In this sense the foresight process has no beginning or end, since it builds on previous and ongoing conversations and consultations and sets in motion learning curves and other intangible spin-offs which are not easily captured in short timeframes" (Cassingena-Harper, 2003, p. 9). Seeking to streamline the process of foresight, I. Miles charts five complementary systemic phases: pre-foresight, recruitment, generation, action, and renewal - stressing on the follow-up, the monitoring and evaluation of the foresight results and opening the discussion on future-thinking capacity building (Miles, 2002).

From a systemic perspective, foresight can significantly improve the policy formulation processes (and - at institutional scale - the strategic processes) in that it is firstly "stressing the possibility of different futures (or future states), as opposed to the assumption that there is an already given, pre-determined future, and hence highlighting the opportunity of shaping our futures. Further, it can enhance flexibility in policy making and implementation, broaden perspectives, and encourage thinking outside the box (think of the unthinkable)" (Havas, 2011, p. 5). For that matter, Da Costa et al. (2008) identity six functions of foresight for the policy formulation process: 
- informing policy - providing anticipatory intelligence on the dynamics of change (future trends and challenges, weak signals, emerging issues and opportunities, etc.) as input along the policy formulation process at various stages;

- facilitating policy implementation - which is an outcome of the foresight process, i.e., new linkages, networks and communities, and also shared awareness and commitment of the stakeholders (involved in the foresight exercise) on the current situation, challenges and vision;

- embedding participation in policy-making - given the participatory characteristic of foresight, facilitating the involvement of different stakeholders in the decision-making process ensures its legitimacy, but also enables mutual learning within the system;

- supporting policy definition - i.e., translating knowledge outcomes from the participatory process into policy options;

- reconfiguring the policy system - in a policy learning curve, so that it is becoming more capable to address long-term challenges;

- the symbolic function - implying that the policy decisions are based on evidence.

This "maturity model" of foresight practices over the last three decades (especially for Science \& Innovation) describes the emergence and shaping of various custom-designed conceptual frameworks and methodologies to address systemic challenges of other related sectors or subsectors.

Such is the case of the Romanian foresight exercise for higher education carried between 2008 and 2011: the exercise deployed a systemic foresight approach to understand the main challenges and propose a systemic transformation (Andreescu, 2012). It aimed to generate a success image of Romanian higher education in 2025 ( $a$ world of ...), based on a wide process of consultation with actors and stakeholders, to define the sets of values and the institutional framework (for which we believe in...) underlying the vision, and to identify the appropriate lines of action (accordingly, we act for ...) needed to materialise the vision. In doing so, the foresight exercise served as a platform for international dialogue, consolidating the most relevant expertise and delivering - among other outputs - a methodological guide for implementing foresight in universities - particularly in the Romanian universities (Curaj et al., 2010). The guide is advancing a conceptual framework for systemic foresight in universities, mixing various methodological options for action to be described hereinafter.

Concerning the practicalities of the foresight tools, attempting to enclose the methodological choices of foresight - as forward-looking activities - in the complex landscape of business, innovation and social-economic studies, paradigms and methods, Miles et al. (2002) note that it encompasses a wider range of approaches used in planning, networking and the management of group processes, as well as organisational learning. There is, in fact, a very wide range of foresight-relevant and typically used methods available; a comprehensive collection of 44 of them has been described by R. Popper under his "foresight diamond", being grouped into creativity-based, expertise-based, interactionbased, and evidence-based methods (an update of the 33 methods described previously (Popper, 2008) (Figure no. 2). 


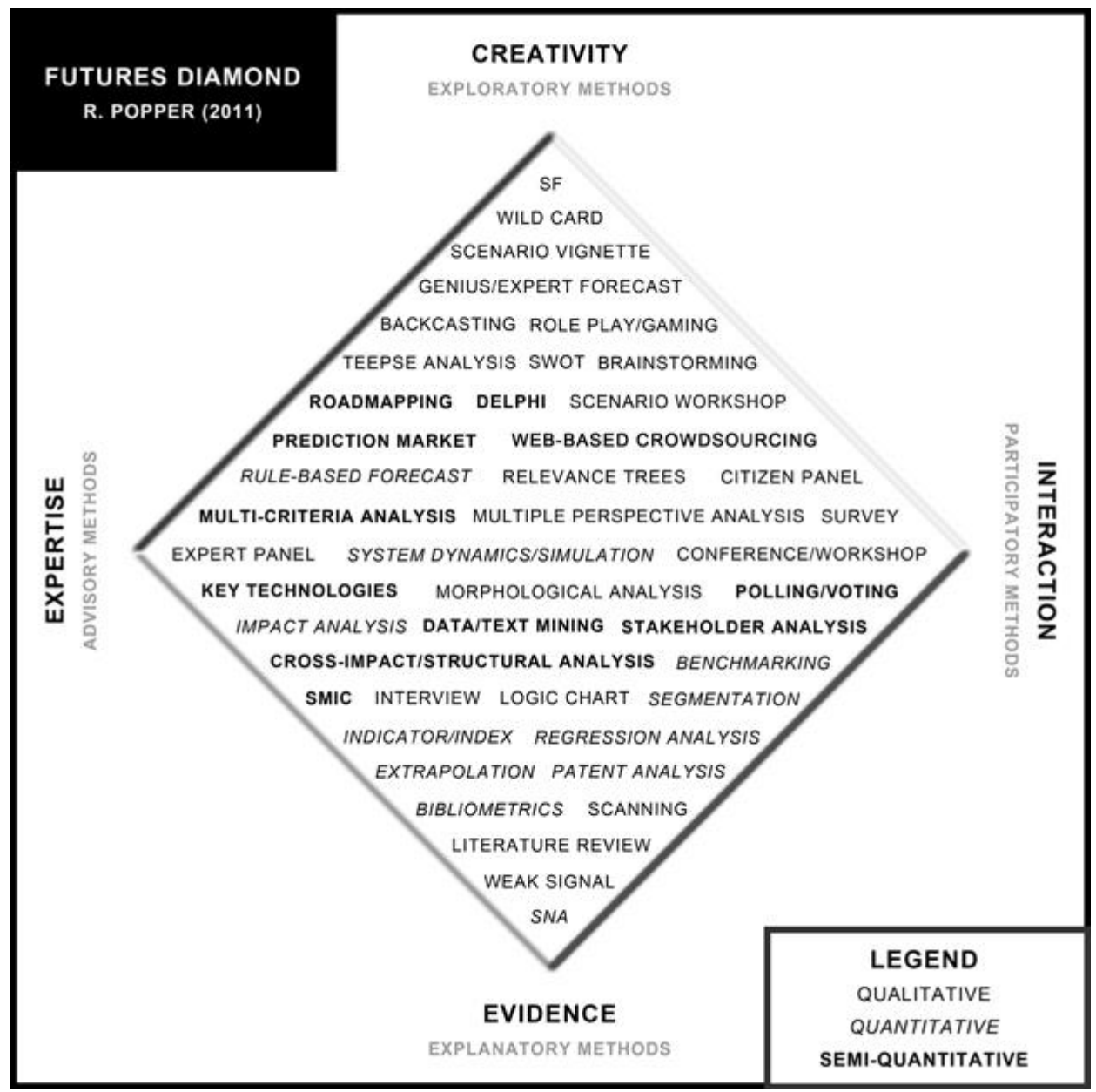

Figure no. 2. The Foresight Diamond (collection of foresight methods) Source: Popper, 2008, p. 46.

The scientific literature and available foresight reports acknowledge that that is no ideal methodological scheme providing the best combination or number of methods, but that the various systemic approaches depend on the particular contexts and rationales of the foresight exercise (European Commission, 2009).

\section{Outlining systemic foresight frameworks}

Given the systemic nature of foresight and in order to cater a full-fledged approach for strategic planning purposes, Curaj et al. (2010) defined five principles of this kind of exercise under the Systemic Foresight Methodology (SFM), provided by the methodological guide for organising it within the Romanian universities. Those principles should assist the practice of foresight by essentially generating a creative inquiry within the space of a higher education institution for designing a future institutional system to fulfil relevant goals and expectations. The authors suggested the following five pillars of 
systemic foresight: systemic understanding, systems synthesis, systemic analysis and selection, system transformation and systemic action, also indicating the most suitable foresight methods for each pillar/stage.

- Systemic understanding

This stage of the foresight exercise should aim to generate a shared understanding of the main current issues and it involves a plain view of the system and its problems - plain in that in this phase a foresight exercise should not be set at clarifying fundamental assumptions, but rather at reaching a more or less general acknowledgement on a set of issues that the system is facing. "The aim is not necessarily to bring about a convergence of views; however, at least a partial convergence is likely to emerge from this process in practice" (Curaj et al., 2010, p. 24).

- Systems synthesis

This second pillar/stage of the foresight exercise is concerned with synthesising the input from scanning into various diagnoses of the current situation and its features. This is advisable to be achieved by building a coherent set of representations of the system and its parts, and of the causal and functional relations between them. "Visual representation tools are extremely valuable to understand systems, their elements and the relationships between them. The outputs of this phase are the "models of the future», which do not necessarily pretend to be complete and quantifiable, but lead to the creation of various alternative scenarios for the future" (Curaj et al., 2010, p. 26).

- Systemic analysis and selection

This stage is seeking to analyse the alternative scenarios for the future and to prioritise them, to a certain extent, through comprehensive negotiations among the experts and stakeholders of the system. The aim is to create a model of the future that is reflecting a collective agreement. An example of such a sequence: a scenario-building phase followed by a debate with stakeholders for validating (or prioritising) the resulting scenario(s), and a final expert-based stage in which the output is refined to serve the policy design. "During this process, decisions on the desired future system need to be aligned with the normative goals and values; the definition of the «most desirable» future system is a matter of prioritisation" (Curaj et al., 2010, p. 27).

\section{- System transformation}

The system transformation stage of the foresight exercise is concerned with tracing the connection between the future scenario describing the desirable future and the present. It is an essential part - in operational terms with regard to policy/strategic formulation - of the process of translating outcomes from the collective process into strategic options. "A backcasting or roadmapping procedure would be beneficial to define the steps of the transformation process in the long, medium and short run" (Curaj et al., 2010, p. 27).

- Systemic action

The systemic action phase is usually the most challenging one, consisting in the elaboration of plans meant to inform present-day decisions for immediate change in order to provide the expected structural and behavioural transformations, considering various systemic capabilities, such as adapting, influencing and shaping the context, as well as selfmodelling virtuously in that context. 


\section{Identifying weak signals in organizations}

The term "weak signals" is brought into the future-oriented dialogue when discussing change, especially technological change. It is about what is "flickering" on the horizon. The first and major challenge is to define it. The scientific literature offers two perspectives: an organisational one, stemming from the field of management, which is less concerned with an in-depth definition of weak signals, but rather oriented towards the way in which they can be integrated in strategic decisions; and a global, more theoretical and abstract one, associated with "futures" studies, focusing on classifying weak signals.

- The organisational perspective. I. Ansoff introduced the term and developed a set of conceptual frameworks and operational procedures for an organisation to be able to identify weak-signals / strategic surprises in a turbulent business environment and have the means of a response (Ansoff, 1975). His work focused on early detection in a view of highlighting endangering factors (for organisational strategies). Another preeminent scholar exploring weak signals - different from what is called the "traditional extrapolation" - is M. Godet; he defines a weak signal as being a driver of change barely perceptible in the present, but which will become a strong trend in the future (Godet, 1993). In general, weak signals are considered to be minor events / early indicators of the "symptoms" of future change (Ansoff \& McDonnell, 1990; Nikander, 2002). It is worth adding here that these rather minor events can often have major consequences, generating trends and what the literature is defining as wild cards (low-probability, high-impact events). The organisation perspective is therefore concerned with analysing emerging phenomena in relation to the strategic decision. Practical types of inquiries are: Can one find the means to obtain information on weak signals within an organisation? Is there a correlation between weak signals and the various obstacles that an organisation is facing? How significant is the effort of identifying the weak signals in anticipating the challenges of an organisation? Several practical instruments and tests have been developed to capture that kind of information for reference, see Hiltunen (2007).

- The global perspective (relevant for the rationales of our paper). It places weak signals by structurally looking at the society as an integrated system of economic, political, educational, cultural, scientific and technological structures. Their evolution over time involves an ongoing development of the instruments for analysing the factors that are influencing change, and the future-oriented thinking is advisable in order to tackle complexity and plan for the long term. The commonly used foresight methods for collecting data about and processing weak signals are: semantic analysis, Delphi questionnaires, scenario-building, on-line searching, crawling and clustering, literature review of scientific works on long-term change. On the practicalities of working with weak signals, we should add here that there is a very broad range of sources for the "raw" information: "www" in its entirety, scientific publications, communities of practices, experts' opinions, research and governmental reports, rumours, colleagues.

Given that foresight processes have a strong social dimension by the participatory feature, the social construction of knowledge is the most significant topic when discussing the fundamentals of weak signals theory, and calls for a brief tracing back. Originating from the classic sociology of G.H. Mead, É. Durkheim and M. Weber, the social construction of knowledge (Berger \& Luckmann, 1967) refers to the fact that common knowledge is shaping the actions of individuals, which in turn are shaping the reality and the representations of it - and therefore, reality and knowledge are a constantly evolving fabric; 
the foresight construct additionally builds on the premise that "all knowledge falls into one of these two classes: it is either tacit or rooted in tacit knowledge" (Polanyi, 1969, p. 195). This paradigmatic encapsulation is essential in understanding the methodological constructions of foresight and weak signals; that is because the majority of the weak signals-related initiatives across Europe that have managed to deliver (see, for instance, http://radar.uefiscdi.ro/) are combining artificial intelligence algorithms with human analysts in an incremental process of creating tacit knowledge and digitally "translating" it.

Currently, various mechanisms for identifying weak signals are publicly available through online platforms: www.sigmascan.org (based on document analysis), www.iknowfutures.eu (as a result of an FP7-funded project), www.sesti.info (another FP7 project, stopped in 2011), www.shapingtomorrow.com (business-oriented, available by subscription).

\section{Blending semantic and network analyses}

Universities are faced with the day-to-day challenges of dealing with huge amounts of digital data. From this data, huge as well is the volume of textual information - and in processing terms, this is a big share of data that is rather overlooked, mainly because of the speed at which it is being generated, but also because of its variety. Employing big data algorithms for analysing various corpuses (homogeneous or not) of text can reveal clear conceptual architectures (that are not apprehensible by merely reading, especially when dealing with large amounts of text), emerging strategic topics, variation of key references over a given timeframe, and can assist in informing strategic decisions.

Drawing on the experience of various strategic projects for the Romanian science and innovation and higher education implemented within the last ten years, an integrated methodological framework of semantic and network analysis has been provided for that matter in 2017 - for reference on the actual procedural design, see Holeab et al. (2017).

The aggregate bibliometric method enables the combined operation of complex parametric and non-parametric models, such as structural and loose semantic algorithms together with mathematical and statistical algorithms for dynamic visualisation of data. The underlying theory of the proposed semantic analysis approach is integrating two distinct work models: propositional discourse analysis (Ghiglione et al., 1995) and predicative propositional analysis (Kintsch \& Van Dijk, 1978) focusing on the sentence as the cognitive unit for primary information processing and as the syntactic unit that allows breaking down the discourse.

The methodological process for performing the analysis is rather complex and "mechanical" and consists of:

- for higher accuracy only, a preparatory phase in which the texts to be analysed are formatted and cleaned by removing redundant information (such as summaries, footnotes, bibliographies, acknowledgements and others alike);

- if possible, the processing of various available sources of relevant semantic ontologies - as valuable input for building the semantic dictionary needed for performing the analysis;

- building a semantic dictionary - the analysis scenario (performed with the open source software Tropes for semantic analysis), i.e., a dictionary that is both relevant to the analytical purpose and consistent with the actual semantic content of the texts to be analysed;

Vol. 22 • No. 55 • June 2020 
- building the visual representations (Figure no. 3) of the semantic networks as described by the textual corpus through the employment of force-directed graph layout algorithms on the semantic ontologies, i.e., ForceAtlas2 with LinLog and low-scaling Dissuade Hubs modes distribution showing modularity classes (performed with the open source software Gephi). [Nota bene: " $\mathrm{a}-\mathrm{r}=1$ " in LinLog means that visual densities in the graph denote structural densities, that is when the attraction force of the nodes depends less on distance, and the repulsion force depends more (Noack, 2007). The Dissuade Hubs mode affects the shape of the graph by dividing the attraction force of each node by its degree plus one for nodes it points to, meaning it grants authorities (nodes with a high indegree) a more central position than hubs (nodes with a high outdegree) (Jacomy et al., 2014). The modularity classes describe semantic subnetworks consisting in nodes with strong and complex relations, while between nodes in different modules there are sparse connections.]

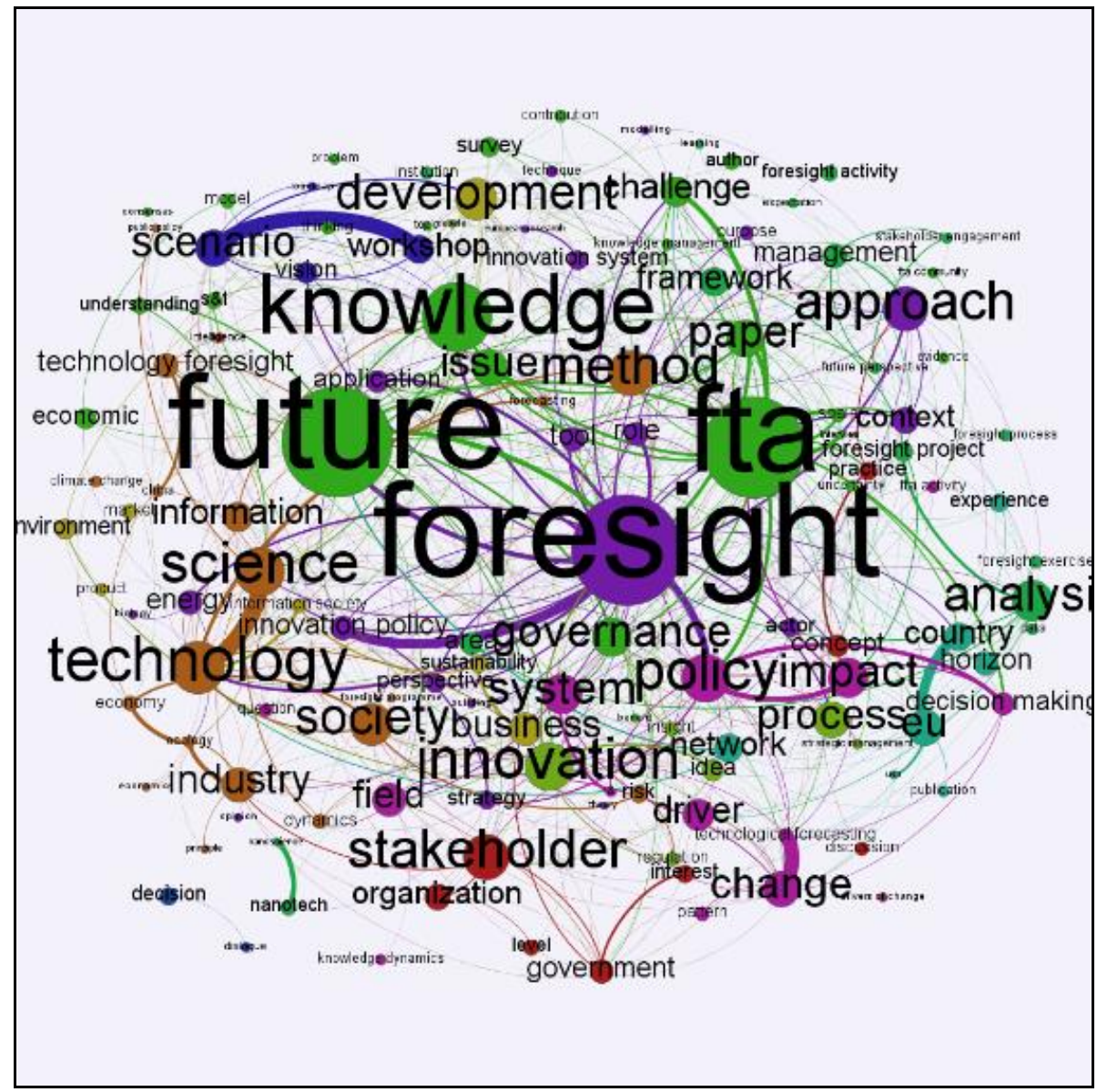

Figure no. 3. Example of a semantic network by the semantic analysis of scientific papers in the field of Future-oriented Technology Analysis

Source: Holeab et al., 2017, p. 34. 


\section{Conclusions}

The paper is conceived as both an analytical and synthetical depiction of the global landscape in which the Romanian universities are functioning and of the challenges they are faced with, doubled by a plea for future-oriented thinking (on foresight), packed in a conceptual framework designed for Romanian universities in their pursuit of taking the lead on sustainable development challenges.

Thus, we began by making an inventory of the feats of the global (educational) landscape, seeing them packed together - not in a "narrative sequence", but in a "complex blend" that universities should tap into by systematically asking the questions (which are neither right nor wrong but should just be). For instance, the digitalisation in higher education cannot occur disconnectedly from a deep understanding of the technological trends that are shaping the digital frontier, which do not take place in a vacuum, but are likewise linked with emerging trends from other sectors - at this intersection, the digital transformation could be demystified and the expected outcomes can be delivered, while ultimately addressing the sustainable development goals with the proper institutional strength (this is only a first example at hand to describe such a blend).

Then, as we think that such complex but mandatory ventures of higher education institutions require specific institutional capacities and resources - with institutional flexibility taking the place of a given recipe of mixing the tools -, we argue that futureoriented thinking is the route. The indicated conceptual framework is a key resource for universities (particularly for those coming from Romania, the educational habitat of the present authors) in taking the lead on sustainable development challenges. In terms of concrete actions, we believe that the frameworks of weak signals identification and semantic analysis would also make for valuable resources in the institutional processes of understanding challenges, technology and change, taking stock of the data, acting and adapting on/to sustainable development.

We aim to foster the dialogue on further building the institutional capacity and refining the tools to address sustainability and invite Romanian universities to take on the challenge. With an eye to the global landscape of higher education, we expect that, in the near future, more case studies, success stories, articulated approaches and best practices will flow from the Romanian higher education system.

\section{References}

Andreescu, L., Gheorghiu, R., Zulean, M. \& Curaj, A., 2012. Systemic Foresight for Higher Education. In Curaj, A., Scott, P., Vlăsceanu, L. and Wilson, L. (Eds.), European Higher Education at the Crossroads: Between the Bologna Process and National Reforms. Dordrecht: Springer Netherlands, pp. 995-1017.

Ansoff, I. \& McDonnell, E., 1990. Implanting Strategic Management (Second edition). New York: Englewood Cliffs: Prentice Hall International Inc.

Ansoff, I., 1975. Managing Strategic Surprise by Response to Weak Signals. Critical Evaluations in Business and Management, 1 December, 18(2), pp. 21-33.

Berger, P. L. \& Luckmann, T., 1967. The Social Construction of Reality. London: Penguin. Cassingena-Harper, J., 2003. Exploring Knowledge Futures in Information and Communications Technologies and Education in 2020 [Report on eFORESEE Malta Foresight Pilot]. Kalkara: Malta Council for Science \& Technology. 
Cassingena-Harper, J., 2013. Impact of Technology Foresight. Compendium of Evidence on the Effectiveness of Innovation Policy Intervention. Manchester: Manchester Institute of Innovation Research, The University of Manchester.

Curaj, A. (coord.), Michel, A., Saritas, O., Rossel, P., Tuomi, I. and Miller, R., 2010. The FOR-UNI Blueprint: A Blueprint for Organizing Foresight in Universities. Bucharest: Romanian Academy Publishing House.

Da Costa, O., Warnke, P., Cagnin, C. \& Scapolo, F., 2008. The Impact of Foresight on Policy-Making: Insights from the FORLEARN Mutual Learning Process. Technology Analysis \& Strategic Management, 20(3), pp. 369-387.

Deloitte Insights, 2019. Tech Trends 2019. Beyond the Digital Frontier (10th Anniversary Edition). London: Deloitte.

European Commission (Directorate-General for Research), 2009. Mapping Foresight. Revealing How Europe and Other World Regions Navigate into the Future [EUR 24041 EN]. Luxembourg: Publications Office of the European Union.

European Commission (JRC), 2010. FOR-LEARN Online Foresight Guide. What is Foresight? [Online].

Future Today Institute, 2019. Tech Trends Report 2019 (12th Annual Edition). New York: Future Today Institute.

Gavigan, J., Keenan, M. \& Miles, I., 2003. Practical Guide to Regional Foresight in the United Kingdom [EUR 20478]. Brussels: CM International; Directorate-General for Research and Innovation, European Commission; Sviluppo Italia; University of Manchester, Policy Research in Engineering Science and Technology.

Ghiglione, R., Kekenbosch, C. \& Landré, A., 1995. L'analyse cognitivo-discursive. Grenoble: Presses Universitaires de Grenoble.

Global University Network for Innovation (GUNi), 2019. Implementing the 2030 Agenda at Higher Education Institutions: Challenges and Responses. Barcelona: Global University Network for Innovation (GUNi).

Godet, M., 1993. From Anticipation to Action: A Handbook of Strategic Prospective. Paris: UNESCO Publishing.

Havas, A., 2011. Governing Policy Processes and Foresight. Potential Contributions and Inherent Tensions. In: On Prospective Technology Studies [KIT SCIENTIFIC REPORTS 7599]. Karlsruhe: KIT Scientific Publishing, pp. 1-18.

Hiltunen, E., 2007. The Futures Window - A Medium for Presenting Visual Weak Signals to Trigger Employees' Futures Thinking in Organizations. Aalto University: Working papers, p. 423.

Holeab, C., Păunică, M. \& Curaj, A., 2017. A Complex Method of Semantic Bibliometrics for Revealing Conceptual Profiles and Trends in Scientific Literature. The Case of Future-Oriented Technology Analysis (FTA) Science. Economic Computation and Economic Cybernetics Studies and Research, 51(2), pp. 3-37.

Jacomy, M., Venturini, T., Heymann, S. \& Bastian, M., 2014. ForceAtlas2, a Continuous Graph Layout Algorithm for Handy Network Visualization Designed for the Gephi Software. PLOS ONE, 9(6).

Kintsch, W. \& Van Dijk, T., 1978. Toward a Model of Text Comprehension and Production. Psychological Review, 85(5), pp. 363-394.

Loveridge, D., 2009. Foresight: The Art and Science of Anticipating the Future. New York and London: Routledge. 
Miles, I., 2002. Appraisal of Alternative Methods and Procedures for Producing Regional Foresight (Report prepared by CRIC for the European Commission's DirectorateGeneral Research funded STRATA-ETAN Expert Group Action). Manchester: CRIC.

Miles, I., Keenan, M. \& Kaivo-Oja, J., 2002. Handbook of Knowledge Society Foresight. Dublin: European Foundation for the Improvement of Living and Working Conditions.

Nikander, I. O., 2002. Early Warnings. A Phenomenon în Project Management (Doctoral dissertation). Helsinki: University of Technology.

Noack, A., 2007. Energy Models for Graph Clustering. Journal of Graph Algorithms and Applications, Volume 11, pp. 453-480.

Păunică, M., Gheorgiu, R., Curaj, A., and Holeab C., 2009. Foresight for Restructuring R\&D Systems. Amfiteatru Economic, 11(25), pp. 2001-2010.

Polanyi, M., 1969. Sense-Giving and Sense-Reading. Chicago, IL: University of Chicago Press.

Popper, R., 2008. Foresight Methodology. In: The Handbook of Technology Foresight. Cheltenham \& Northampton: Edward Elgar, pp. 44-88.

Rampelt, F., Orr, D. \& Knoth, A., 2019. Bologna Digital 2020. White Paper on Digitalisation in the European Higher Education Area. Berlin: Hochschulforum Digitalisierung (HFD).

Wells, H. G., [1932] 1987. Wanted: Professors of Foresight! Futures Research Quarterly, 3(1), pp. 89-91. 